\title{
The critical role of urease in yogurt fermentation with various combinations of Streptococcus thermophilus and Lactobacillus dellbrueckii ssp. bulgaricus
}

\author{
R. Yamauchi, ${ }^{1 *}$ E. Maguin,${ }^{2}$ H. Horiuchi, ${ }^{3}$ M. Hosokawa, ${ }^{4}$ and Y. Sasaki ${ }^{1}$ \\ ${ }^{1}$ Graduate School of Agriculture, University of Meiji, 1-1-1 Higashi-Mita, Tama-ku, Kawasaki, Kanagawa 214-8571, Japan \\ ${ }^{2}$ INRA UMR1319 Micalis Allée de Vilvert Bat. 440, R-1, Pce 420, 78352 Jouy-en-Josas Cedex, lle de France, France \\ ${ }^{3}$ Food Development Laboratories, R\&D Division, Meiji Co., Ltd., 1-29-1 Nanakuni, Hachioji, Tokyo 192-0919, Japan \\ ${ }^{4}$ Chuo University of Junior and High School, 3-22-1 Nukuikitamachi, Koganei, Tokyo, 184-8575, Japan
}

\section{ABSTRACT}

The protocooperation between Streptococcus thermophilus and Lactobacillus delbrueckii ssp. bulgaricus relies on metabolite exchanges that accelerate acidification during yogurt fermentation. Conflicting results have been obtained in terms of the effect of the Strep. thermophilus urease and the $\mathrm{NH}_{3}$ and $\mathrm{CO}_{2}$ that it generates on the rate of acidification in yogurt fermentation. It is difficult to perform a systematic study of the effects of urease on protocooperation because it is necessary to distinguish among the direct, indirect, and strain-specific effects resulting from the combination of the strains of both species. To evaluate the direct effects of urease on protocooperation, we generated 3 ureasedeficient mutants $(\Delta u r e C)$ of fast- and slow-acidifying Strep. thermophilus strains and observed the effects of $\mathrm{NH}_{3}$ or $\mathrm{CO}_{2}$ supplementation on acidification by the $\triangle$ ure $C$ strains. Further, we examined 5 combinations of 3 urease-deficient $\Delta$ ure $C$ strains with $2 \mathrm{CO}_{2}$-responsive or $\mathrm{CO}_{2}$-unresponsive strains of $L$. bulgaricus. Urease deficiency induced a shortage of ammonia nitrogen and $\mathrm{CO}_{2}$ for the fast- and slow-acidifying Strep. thermophilus and for the $\mathrm{CO}_{2}$-responsive L. bulgaricus, respectively. Notably, the shortage of ammonia nitrogen had more severe effects than that of $\mathrm{CO}_{2}$ on yogurt fermentation, even if coculture with $L$. bulgaricus masked the effect of urease deficiency. Our work established (1) that urease deficiency inhibits the fermentative acceleration of protocooperation regardless of the Strep. thermophilus and L. bulgaricus strain combinations, and (2) that urease is an essential factor for effective yogurt acidification. Key words: urease, protocooperation, yogurt fermentation

Received June 11, 2018.

Accepted September 18, 2018.

*Corresponding author: cf60128@meiji.ac.jp

\section{INTRODUCTION}

Yogurt is a traditional fermented food that dates back to 6,000 BCE (Weerathilake et al., 2014). Yogurt is made from milk fermentation by a coculture of Streptococcus thermophilus and Lactobacillus delbrueckii ssp. bulgaricus, 2 lactic acid bacteria (LAB) commonly consumed by humans. Protocooperation exists between these 2 LAB (Tamime and Robinson, 2007); however, some of the interactions between them are ill defined. Today, our understanding of protocooperation is that L. bulgaricus proteolyzes casein with its surface PrtB protease, providing AA and peptides to Strep. thermophilus that, in turn, provides formic acid (Veringa et al., 1968) and carbon dioxide (Galesloot et al., 1968; Driessen et al., 1982) to L. bulgaricus. The growth rate of each species and, consequently, the milk acidification rate are boosted by these metabolite exchanges in cocultures compared with monocultures of each species.

The analysis of protocooperation during yogurt fermentation is complex because it is difficult to (1) distinguish between direct and indirect effects of protocooperation on bacterial growth in cocultures in milk, and (2) have the appropriate controls. Regarding controls, milk monocultures of Strep. thermophilus or $L$. bulgaricus must be supplemented with AA and formate, respectively, to prevent nutrient limitation. Moreover, because the efficiency of protocooperation depends on the combination of Strep. thermophilus and L. bulgaricus strains, using several strains of each species must be considered before drawing general conclusions about protocooperation. To avoid the problem of nutritional limitation in monocultures, we supplemented the milk with (1) peptides that result from the digestion of casein for Strep. thermophilus monocultures, and (2) sodium formate for $L$. bulgaricus monocultures. These culture conditions, called pseudo-cocultures, allowed us to analyze the effects of factors other than limited peptide and formate on growth and acidification. For instance, we found that dissolved oxygen (DO) has an inhibitory effect on protocooperation by showing that DO concen- 
tration in milk had to decrease to almost $0 \mathrm{mg} / \mathrm{kg}$ to allow active acidification by the industrial starter LB81 (comprising Strep. thermophilus 1131 and L. bulgaricus 2038; Horiuchi et al., 2009). Using pseudo-cocultures, we also established that Nox, the NADH oxidase of Strep. thermophilus 1131, was an essential factor for efficient protocooperation as it was the major oxygenconsuming enzyme in the coculture with $L$. bulgaricus 2038 and strongly contributed to the decrease of DO in milk (Sasaki et al., 2014).

Aeration with $\mathrm{N}_{2}$ gas was performed to reduce DO in the milk medium before fermentation. We showed that flushing $\mathrm{N}_{2}$ gas into milk before fermentation shortened the acidification time for both Strep. thermophilus 1131 monoculture and coculture with L. bulgaricus 2038 (Horiuchi and Sasaki, 2012).

The urease enzyme (urea amidohydrolase, EC 3.5.1.5) catalyzes hydrolysis of urea into ammonia and carbon dioxide. Streptococcus thermophilus is the only LAB to display significant urease activity (Iyer et al., 2010). In Strep. thermophilus, the urease cluster has 8 open reading frames, ureI (urea transport homologous), ure $A B C$ (structural genes), and ureEFGD (accessory genes) (Mora et al., 2004).

Effective acidification of Strep. thermophilus and $L$. bulgaricus coculture is important for yogurt fermentation. Effective acidification may prevent the outgrowth of contaminants and decrease the production cost of the fermentation process. Urease produced by Strep. thermophilus is thought to provide $\mathrm{CO}_{2}$ to L. bulgaricus and stimulate its acidification; however, there are conflicting reports regarding the role of urease in yogurt fermentation. Arioli et al. (2017) showed that urea hydrolysis by Strep. thermophilus urease increased the bacterial population in the coculture of Strep. thermophilus CNRZ385 and L. bulgaricus MIM91. In contrast, Mora et al. (2004) reported that when Strep. thermophilus DSM $20167^{\mathrm{T}}$ wild type or its derived urease-deficient mutant A16 were cocultured with $L$. bulgaricus ATCC $11842^{\mathrm{T}}$ in the presence of urea, the acidification rate was higher with the urease-deficient mutant than with the wild-type strain. They proposed that ammonia generated by Strep. thermophilus urease had a buffering effect that reduced the rate of $\mathrm{pH}$ decrease and decreased the acidification rate of the Strep. thermophilus - L. bulgaricus coculture. Because both studies reached different conclusions and only used 1 or 2 strains in culture, it is impossible to draw a general conclusion on the importance of urease. In this work, we performed a more systematic analysis with several strain combinations of Strep. thermophilus and L. bulgaricus to determine the role of urease for this economically important coculture. We used 3 fast- and slow-acidifying strains of Strep. thermophilus plus their ure $C$-deficient mutants $(\Delta u r e C)$, and $7 \mathrm{~L}$. bulgaricus strains, 4 that were stimulated by $\mathrm{CO}_{2}\left(\mathrm{CO}_{2-}\right.$ responsive) and $3 \mathrm{CO}_{2}$-unresponsive strains, as well as 5 strain combinations for cocultures. This experimental setting allowed us to clarify the role of urease in yogurt fermentation.

\section{MATERIALS AND METHODS}

\section{Bacterial Strains and Growth Conditions}

Table 1 shows the strains and plasmids used in this work. Strains included 3 strains of Strep. thermophilus: ATCC19258 ${ }^{\mathrm{T}}$, ST1131, and ST499; and 7 strains of L. bulgaricus: ATCC11842 ${ }^{\mathrm{T}}$, LB2038, LB494, LB496, LB497, LB536, and LB600. Streptococcus thermophilus ST1131 and ST499 and L. bulgaricus LB494, LB496, LB497, LB2038, LB600, and LB536 were obtained from the Food Research and Development Center, Meiji Dairies Corporation (Tokyo, Japan). These strains have been used in the commercial production of yogurt and their acidification is much faster than that of type strains.

Streptococcus thermophilus and L. bulgaricus strains were cultured at $37^{\circ} \mathrm{C}$ for 16 to $18 \mathrm{~h}$ in $1 / 2 \mathrm{M} 17$ broth (Becton, Dickinson and Co., Franklin Lakes, NJ) supplemented with $1 \%$ lactose and 1/2 de Man, Rogosa, and Sharpe (MRS) broth (Becton, Dickinson and Co.), respectively. After storage at $4^{\circ} \mathrm{C}$ up to $7 \mathrm{~h}$, the cultures were inoculated at $1 \%(\mathrm{vol} / \mathrm{vol})$ in fresh medium and cultured at $37^{\circ} \mathrm{C}$ for 16 to $18 \mathrm{~h}$. These cultures were then used for inoculation of the various milk media.

Monocultures of Strep. thermophilus or L. bulgaricus were cultured in skim milk medium supplemented with $0.1 \%$ peptides that result from the digestion of casein (CE90GMM, Nippon Shinyaku Ltd., Kyoto, Japan) or $1 \mathrm{~m} M$ sodium formate (Wako Pure Chemical Industries Ltd., Osaka, Japan), respectively, and inoculated at a final optical density (OD) value at $660 \mathrm{~nm}\left(\mathrm{OD}_{660}\right)$ of 0.05. The coculture of Strep. thermophilus and $L$. bulgaricus was inoculated at a 1:1 ratio with a final $\mathrm{OD}_{660}$ of 0.05 in skim milk medium with $0.4 \mathrm{~g} / \mathrm{L}$ urea (Wako Pure Chemical Industries Ltd.) when necessary. The skim milk medium contained $10 \%$ (vol/vol) skim milk powder and was sterilized by heating at $95^{\circ} \mathrm{C}$ for 2 min and immediately cooled to $45^{\circ} \mathrm{C}$ to prevent formate production by autoclave treatment. Gas flushing with $\mathrm{N}_{2}$ was performed to decrease $\mathrm{CO}_{2}$ and dissolved oxygen in the skim milk medium. The $\mathrm{N}_{2}$ gas was filtered with a $0.45-\mu \mathrm{m}$ cellulose acetate filter, and flushing was performed as previously described (Horiuchi et al., 2009).

Monocultures and cocultures were carried out at $43^{\circ} \mathrm{C}$ under 4 conditions in skim milk medium: (1) without $\mathrm{N}_{2}$ flushing, (2) with $\mathrm{N}_{2}$ flushing (15 min), (3) with 
Table 1. Bacterial strains and plasmids

\begin{tabular}{lll}
\hline Strain or plasmid & Relevant phenotype & Reference \\
\hline Streptococcus thermophilus & & Mora et al. (2004) \\
ATCC19258 & Slow-acidifying strain & Sasaki et al. (2014) \\
ST1131 & Fast-acidifying strain & This study \\
ST499 & Fast-acidifying strain & Mora et al. (2004) \\
Lactobacillus delbrueckii ssp. bulgaricus & & Sasaki et al. (2014) \\
ATCC11842 & $\mathrm{CO}_{2}$-unresponsive & This study \\
LB2038 & $\mathrm{CO}_{2}$-responsive & This study \\
LB494 & $\mathrm{CO}_{2}$-responsive & This study \\
LB496 & $\mathrm{CO}_{2}$-unresponsive & This study \\
LB497 & $\mathrm{CO}_{2}$-responsive & This study \\
LB536 & $\mathrm{CO}_{2}$-responsive & \\
LB600 & $\mathrm{CO}_{2}$-unresponsive & Maguin et al. (1996) \\
Plasmid & $\mathrm{Em}^{\mathrm{r}}$ 1 thermo-sensitive replicon & This study \\
pG ${ }^{+}$host6 & $\mathrm{pG}^{+}$host6 containing a deleted ureC fragment, Em ${ }^{\mathrm{r}}$ & \\
pG ${ }^{+}$urC69 & &
\end{tabular}

${ }^{1}$ Erythromycin-resistant.

$\mathrm{N}_{2}$ flushing and supplemented with $30 \mathrm{mM} \mathrm{NaHCO}$ (4) with $\mathrm{N}_{2}$ flushing and supplemented with $30 \mathrm{mM}$ $\mathrm{NaHCO}_{3}$ and $10 \mathrm{mM}\left(\mathrm{NH}_{4}\right)_{2} \mathrm{SO}_{4}$. Plastic test tubes were used for cultures without $\mathrm{N}_{2}$ flushing and tightly closed glass tubes were used after $\mathrm{N}_{2}$ flushing.

\section{Measurement of Acidity of Fermentation}

Acidity was measured by titrating a 9-g milk sample against $0.1 \mathrm{~N} \mathrm{NaOH}$ using phenolphthalein as an indicator. Acidity (\%) is calculated by using the following formula:

Acidity $(\%)=0.1 \mathrm{~N} \mathrm{NaOH}$ titer $(\mathrm{mL}) \times 0.1 \times$ factor,

where factor was measured by titrating $0.1 \mathrm{~N} \mathrm{NaOH}$ we made against $0.1 \mathrm{~mol} / \mathrm{L}$ hydrochloric acid (Wako Pure Chemical Industries Ltd.) using phenolphthalein as an indicator. The acidification rate was determined by the acidity increase per minute in a milk sample.

\section{Construction of ureC Knockout Mutants of Strep. thermophilus}

The construction of the ure $C$ knockout mutants ( $\Delta$ ureC) of Strep. thermophilus ATCC19258 ${ }^{\mathrm{T}}$, ST1131, and ST499 was based on the method described by Mora et al. (2004). According to the Kyoto Encyclopedia of Genes and Genomes (KEGG), the sequence of the urease cluster is highly conserved among 8 strains of Strep. thermophilus. The ureC gene of ST1131 was amplified with primers LAB099 and LAB102 and cloned (Figure 1).

The 693-bp in-frame deletion of ure $C$ was obtained by PCR using primers LAB099 and LAB100 to obtain fragment 1 first and then primers LAB101 and
LAB102 to amplify fragment 2. Then, primers LAB099 and LAB102 were used to generate a 1,026-bp fragment combining fragments 1 and 2 (Figure 1). This 1,026bp fragment was inserted at the XbaI and XhoI sites of $\mathrm{pG}^{+}$host6 (thermo-sensitive replicon, Appligene, Pleasanton, CA) to generate the $\mathrm{pG}^{+}$urC69 plasmid. The $\mathrm{pG}^{+}$urC69 plasmid was first electroporated into Lactococcus lactis IL1403; then, plasmid DNA was then prepared and electroporated into Strep. thermophilus ATCC19258 ${ }^{\mathrm{T}}$, ST1131, or ST499. The expected gene replacements were induced via the double crossover events as previously described (Biswas et al., 1993). The ure $C$ knockout mutants of Strep. thermophilus

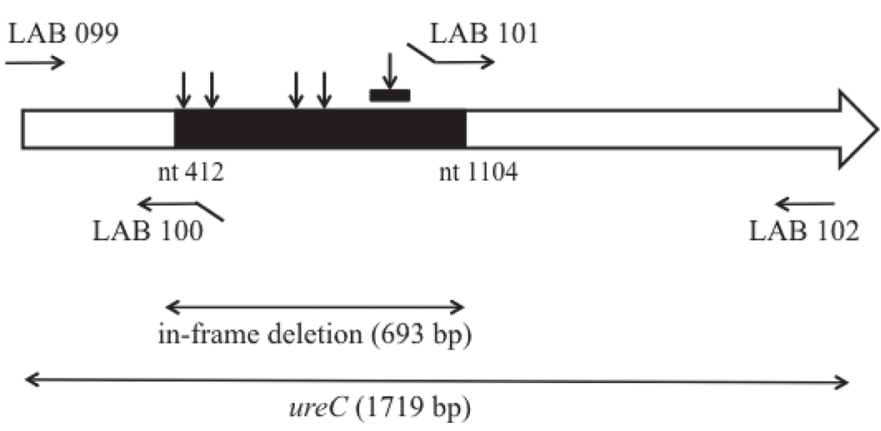

Figure 1. Schematic representation of the Streptococcus thermophilus ure $C$ gene. The ure C gene of Strep. thermophilus ST1131 was used to generate a 1,026-bp fragment with a 693-bp in-frame deletion from nucleotides (nt) 412 to 1104 . The vertical arrows represent the codons encoding histidine residue H138, H140, H223, H250, and H324. The small black rectangle indicates the location of the active site (nt 961 to 981). The primers (horizontal arrows) used to generate the deletion were LAB 099 (nt 1 to 25), LAB 100 (nt 398 to 411 and nt 1105 to 1118), LAB101 (nt 1105 to 1118 and nt 398 to 411), and LAB102 (nt 1695 to 1719). LAB $099=$ GACCTCGAGATGAGTTTTAAAATGGATCGTGAAG; LAB100 = TCACCGACACGTCCGAGGTCAATACCAC; LAB101 $=$ GTGGTATTGACCTCGGACGTGTCGGTGA; LAB102 = GCGTCTAGATTAGAACAAGAAATAACGTTGAGAC. 
ATCC19258 ${ }^{\mathrm{T}}$, ST1131, and ST499 were validated by sequencing the ure $C$ genes or by PCR to confirm the 693-bp deletion (data not shown) and were designated $\Delta$ ure $C 19258^{\mathrm{T}}, \Delta$ ure $C 1131$, and $\Delta$ ure $C 499$, respectively.

\section{Measurement of $\mathrm{CO}_{2}$ and $\mathrm{NH}_{3}$ Produced by Strep. thermophilus Wild Type and $\triangle$ ureC}

Wild-type (WT) Strep. thermophilus and $\Delta$ ure $C$ derivative cultures were used to inoculate at a final $\mathrm{OD}_{660}$ of 0.05 in skim milk supplemented with $0.1 \%$ casein digested peptides and $0.4 \mathrm{~g} / \mathrm{L}$ urea and, only for $\mathrm{CO}_{2}$ measurement, flushed with $\mathrm{N}_{2}$ gas for $30 \mathrm{~min}$. These cultures were transferred to tightly closed glass bottles without headspace for $\mathrm{CO}_{2}$ measurement or to plastic test tubes for $\mathrm{NH}_{3}$ measurement and incubated at $43^{\circ} \mathrm{C}$. After $6 \mathrm{~h}$ of cultivation, the $\mathrm{CO}_{2}$ concentration of the medium was determined by a glass electrode method using a $\mathrm{CO}_{2}$ concentration meter (CGP-31, DKK-TOA, Tokyo, Japan). For $\mathrm{NH}_{4}-\mathrm{N}$ measurement, sample and deproteinization agent (Wako Pure Chemical Industries. Ltd.) were mixed and centrifuged at 15,133 $\times g$ for $10 \mathrm{~min}$ at $4^{\circ} \mathrm{C}$. The supernatant was filtered with a $0.22-\mu \mathrm{m}$ cellulose acetate filter and used for $\mathrm{NH}_{4}-\mathrm{N}$ measurement by ammonia test (Wako Pure Chemical Industries Ltd.). The calibration curve using $\mathrm{NH}_{4} \mathrm{Cl}$ ranged from 1 to $8 \mathrm{mg} / \mathrm{L} \mathrm{NH}_{4}-\mathrm{N}$ for $\mathrm{WT}$ and 1 to 4 $\mathrm{mg} / \mathrm{L} \mathrm{NH}_{4}-\mathrm{N}$ for $\Delta$ ureC.

\section{Urease Assay}

Cells were centrifuged at $6,726 \times g$ for 5 min at $4^{\circ} \mathrm{C}$, washed 3 times in $50 \mathrm{mM}$ sodium phosphate buffer (pH 7.0), suspended in the same buffer, transferred to a screw-cap tube containing glass beads (0.105-0.125 $\mathrm{mm}$ ) in an amount equivalent to the cell suspension weight, and then disrupted at $6.5 \mathrm{~m} / \mathrm{s}$ for $30 \mathrm{~s}$ using a Fast Prep-24 instrument (MP Biomedicals, San Diego, $\mathrm{CA})$. The homogenate was centrifuged at $10,509 \times g$ for $15 \mathrm{~min}$ at $4^{\circ} \mathrm{C}$, and the supernatant was used for the urease assay. Total protein concentration of the supernatant was determined by the Bradford method (Bradford, 1976) using BSA as a standard. Urease activity was determined by measurement of released $\mathrm{NH}_{4-}$ $\mathrm{N}$ as follows: $250 \mu \mathrm{L}$ of supernatant containing 1 to 4 $\mu \mathrm{g}$ of protein for WT strains or 5 to $16 \mu \mathrm{g}$ of protein for $\Delta$ ure $C$ strains was mixed with $250 \mu \mathrm{L}$ of $100 \mathrm{mM}$ urea solution and incubated at $37^{\circ} \mathrm{C}$ for $30 \mathrm{~min}$. After incubation, $250 \mu \mathrm{L}$ of the solution was transferred into a $2.0-\mathrm{mL}$ tube containing deproteinization agent (Wako Pure Chemical Industries. Ltd.) and mixed. This mixture was centrifuged at $15,133 \times g$ for $10 \mathrm{~min}$ at $4^{\circ} \mathrm{C}$, and the supernatant was filtered with $0.22-\mu \mathrm{m}$ cellulose acetate filter. Total $\mathrm{NH}_{4}-\mathrm{N}$ concentrations in the filtered supernatant were determined by using ammonia test (Wako Pure Chemical Industries Ltd.). The calibration curve using $\mathrm{NH}_{4} \mathrm{Cl}$ ranged from 1 to $8 \mathrm{mg} / \mathrm{L}$ $\mathrm{NH}_{4}-\mathrm{N}$. Urease activity was determined as the amount of released $\mathrm{NH}_{4}-\mathrm{N}$ for 1 min per $1 \mu \mathrm{g}$ of protein.

\section{Measurement of Urea in Skim Milk}

Measurement of urea in skim milk was based on a previously described method (Food Safety and Standards Authority of India, 2015). First, $5 \mathrm{~mL}$ of skim milk sample and $5 \mathrm{~mL}$ of $24 \%$ trichloroacetic acid were mixed and centrifuged at $15,133 \times g$ for $10 \mathrm{~min}$ at $4^{\circ} \mathrm{C}$. The supernatant was filtered with filter paper; then, $900 \mu \mathrm{L}$ of filtered supernatant and $900 \mu \mathrm{L}$ of $p$-dimeth$\mathrm{yl}$ amino benzaldehyde solution (1.6 $\mathrm{g}$ of $p$-dimethyl amino benzaldehyde dissolved in $100 \mathrm{~mL}$ of ethanol and $10 \mathrm{~mL}$ of concentrated $\mathrm{HCl}$ added) were mixed and left standing for $10 \mathrm{~min}$ at room temperature. Then, optical density was measured at $420 \mathrm{~nm}$. The amount of urea in the skim milk sample was calculated based on a standard curve.

\section{Statistical Analysis}

Statistical analysis was performed by using the analysis tool of Excel 2007 (Microsoft Corp., Redmond, WA). A $P$-value less than 0.05 was considered statistically significant.

\section{RESULTS}

\section{Characterization of 3 WT Strep. thermophilus Strains and Urease Knockout Derivatives}

We generated urease knockout mutants $(\Delta$ ure $C$ ) for the 3 Strep. thermophilus strains studied in this work; that is, ST1131, ST499, and ATCC19258 ${ }^{\mathrm{T}}$, using double crossover gene replacement leading to an in-frame deletion of $693 \mathrm{bp}$ (Figure 1) in the ure $C$ gene. Because this 693-bp region contained the codons for the 5 histidine residues (H138, H140, H250, H223, and H324) required for nickel and substrate binding and the presumed active site MVCHHLD (AA 321 to 327; Figure 1, Mora et al., 2004), we predicted that the deleted gene product would be inactive. However, to confirm our prediction, $\mathrm{WT}$ and $\triangle$ ure $C$ strains were characterized for urease activity and $\mathrm{CO}_{2}$ and $\mathrm{NH}_{3}$ production (Table 2). In addition, we monitored the biomass obtained with monocultures cultured in supplemented skim milk or $1 / 2$ M17 broth supplemented with $1 \%$ lactose (Table $2)$. 
Table 2. Urease activity, $\mathrm{CO}_{2}$ and $\mathrm{NH}_{3}$ production, and counts (cfu) of Streptococcus thermophilus wild type and urease-deficient mutants $(\Delta$ ure $C)$ isogenic strains ${ }^{1}$

\begin{tabular}{|c|c|c|c|c|}
\hline Item & $\begin{array}{c}\text { Urease activity }{ }^{2} \\
(\mathrm{mg} / \mathrm{L} \cdot \mathrm{min} \cdot \mu \mathrm{g} \text { of protein })\end{array}$ & $\mathrm{CO}_{2}^{3}(\mathrm{mg} / \mathrm{L})$ & $\mathrm{NH}_{4}-\mathrm{N}^{4}(\mathrm{mg} / \mathrm{L})$ & Count (cfu) \\
\hline \multicolumn{5}{|l|}{ Wild type } \\
\hline ATCC $19258^{\mathrm{T}}$ & $2.0 \pm 0.65$ & $5.0 \pm 0.57 \times 10^{2}$ & $2.5 \pm 0.08 \times 10^{2}$ & $1.5 \pm 0.45 \times 10^{8}$ \\
\hline ST499 & $1.9 \pm 0.40$ & $5.6 \pm 0.71 \times 10^{2}$ & $2.1 \pm 0.15 \times 10^{2}$ & $3.4 \pm 0.85 \times 10^{8}$ \\
\hline \multicolumn{5}{|c|}{ Urease-deficient mutants $(\Delta$ ure $C)$} \\
\hline$\Delta$ ure $19258^{\mathrm{T}}$ & $\mathrm{ND}^{5}$ & $7.3 \pm 1^{*}$ & ND & $1.7 \pm 0.95 \times 10^{7 *}$ \\
\hline Medium $^{6}$ & -5 & ND & 2.7 & - \\
\hline
\end{tabular}

${ }^{1}$ The plus/minus values show SD of the results from at least 3 independent experiments.

${ }^{2}$ Amount of released $\mathrm{NH}_{4}-\mathrm{N}$ in 1 min per $\mu \mathrm{g}$ of protein.

${ }^{3}$ Amount of $\mathrm{CO}_{2}$ in the culture after cultivation $(6 \mathrm{~h})$.

${ }^{4} \mathrm{Amount}$ of $\mathrm{NH}_{4} \mathrm{~N}$ in the culture after cultivation $(6 \mathrm{~h})$.

${ }^{5} \mathrm{ND}=$ below detection threshold; $-=$ not performed.

${ }^{6}$ Uninoculated skim milk supplemented with urea $(0.4 \mathrm{~g} / \mathrm{L})$.

*Numbers with asterisks are significant $(P=0.05)$ vs. wild type.

The urease activity of ST1131, ST499, and ATCC19258 ${ }^{\mathrm{T}}$ was $1.0,1.9$, and $2.0 \mathrm{mg} / \mathrm{L} \cdot \mathrm{min} \cdot \mu \mathrm{g}$ of protein, respectively, whereas the activity of their knockout derivatives ( $\Delta$ ure $C$ 1131, $\Delta$ ure $C$ 499, and $\Delta$ ure $C 19258^{\mathrm{T}}$ ) was below the detection limit. We also determined $\mathrm{CO}_{2}$ and $\mathrm{NH}_{3}$ production levels in these Strep. thermophilus cultures. The concentrations of $\mathrm{CO}_{2}$ in the cultures of ST1131, ST499, and ATCC19258 $8^{\mathrm{T}}$ were $4.6 \times 10^{2}, 5.6 \times 10^{2}$, and $5.0 \times 10^{2} \mathrm{mg} / \mathrm{L}$, respectively, whereas $\mathrm{CO}_{2}$ was not detectable in the medium, which was flushed with $\mathrm{N}_{2}$ gas before incubation. In the $\Delta$ ure $C 1131, \Delta$ ure $C 499$, and $\Delta$ ure $C 19258^{\mathrm{T}}$ cultures, $\mathrm{CO}_{2}$ concentrations were $6.4,7.6$, and $7.3 \mathrm{mg} / \mathrm{L}$, respectively, showing a decrease to at least $1.5 \%$ of the cultures of their isogenic WT counterparts (Table 2).

In uninoculated skim milk medium after $\mathrm{N}_{2}$ gas aeration, the concentration of $\mathrm{NH}_{4}-\mathrm{N}$ was $2.7 \mathrm{mg} / \mathrm{L}$. The concentrations of $\mathrm{NH}_{4}-\mathrm{N}$ in the ST1131, ST499, and ATCC19258 ${ }^{\mathrm{T}}$ cultures were $2.2 \times 10^{2}, 2.1 \times 10^{2}$, and $2.5 \times 10^{2} \mathrm{mg} / \mathrm{L}$, respectively, whereas $\mathrm{NH}_{4}-\mathrm{N}$ could not be detected in any of the $\Delta$ ure $C$ cultures.

Because inactivation of urease was confirmed for all $\triangle$ ure $C$ strains at both the molecular and phenotypic levels, counts of Strep. thermophilus WT and $\Delta$ ureC strains were determined to evaluate the effect of urease deficiency on growth. The counts (cfu/mL of culture) were always lower with $\Delta$ ure $C$ strains compared with their WT counterparts albeit with some variation. The counts were $6.0 \times 10^{9} \mathrm{cfu}$ for ST1131 and $1.1 \times 10^{8}$ cfu for $\Delta$ ure C1131 (i.e., decrease to $1.8 \%$ of WT), 3.4 $\times 10^{8} \mathrm{cfu}$ for ST499 and $2.4 \times 10^{7} \mathrm{cfu}$ for $\Delta$ ure C499 (i.e., decrease to $7.1 \%$ of WT), and $1.5 \times 10^{8} \mathrm{cfu}$ for ATCC $19258^{\mathrm{T}}$ and $1.7 \times 10^{7}$ cfu for $\Delta$ ure $C 19258^{\mathrm{T}}$ (i.e., decrease to $11.3 \%$ of WT). These data showed that urease deficiency significantly limited the proliferation of all 3 Strep. thermophilus strains.

\section{Effect of $\mathrm{NaHCO}_{3}$ and $\left(\mathrm{NH}_{4}\right)_{2} \mathrm{SO}_{4}$ Supplementation on Acid Production of UreC Knockout Strains}

The acidification curves of Strep. thermophilus WT strains and their $\Delta$ ure $C$ derivatives were monitored in skim milk supplemented with urea $(0.4 \mathrm{~g} / \mathrm{L})$ and casein digested peptides, and flushed with $\mathrm{N}_{2}$ to eliminate the dissolved $\mathrm{CO}_{2}$ (Figure 2). Based on the observed acidification rates, we distinguished (1) the fast-acidifying strains ST1131 and ST499, which required $3 \mathrm{~h}$ to reach $0.5 \%$ acidity, and (2) the slow-acidifying strain ATCC $19258^{\mathrm{T}}$, which required $9 \mathrm{~h}$. However, for all 3 strains, urease deficiency led to a dramatic decrease in acidification rates (Figure 2).

To evaluate whether $\mathrm{CO}_{2}$ or $\mathrm{NH}_{3}$ provided by the urease activity affected the acidification rate of Strep. thermophilus strains, $\mathrm{NaHCO}_{3}$ and $\left(\mathrm{NH}_{4}\right)_{2} \mathrm{SO}_{4}$ were supplemented as sources of $\mathrm{CO}_{2}$ and $\mathrm{NH}_{3}$ to WT and $\Delta$ ure $C$ monocultures. For all $3 \mathrm{WT}$ strains, $\mathrm{NaHCO}_{3}$ and $\left(\mathrm{NH}_{4}\right)_{2} \mathrm{SO}_{4}$ supplementation mostly did not stimulate acidification (data not shown). For the 2 $\Delta$ ure $C$ strains ( $\Delta$ ureC499 and $\Delta$ ureC1131), $\mathrm{NaHCO}_{3}$ supplementation slightly accelerated the acidification rates, whereas supplementation with $\mathrm{NaHCO}_{3}$ and $\left(\mathrm{NH}_{4}\right) 2 \mathrm{SO}_{4}$ nearly recovered the acidification rates of $\Delta$ ure $C 499$ and $\Delta$ ure $C 1131$ similar to that of their WT counterparts. The effect of the double supplementation on the growth of $\Delta$ ure $C 19258 \mathrm{~T}$ remained limited. 

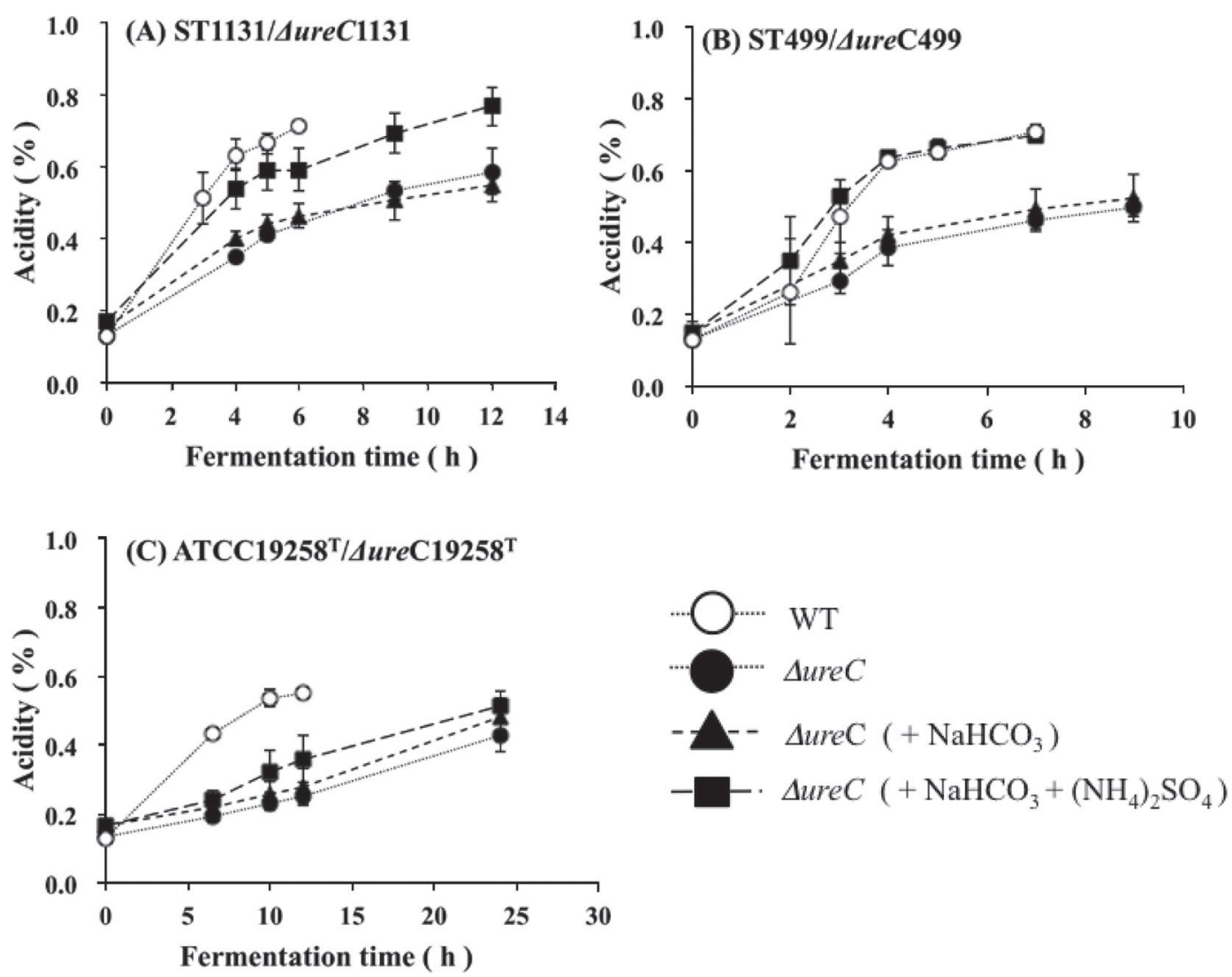

Figure 2. Acidification kinetics in wild type (WT) and urease-deficient ( $\Delta$ ureC) Streptococcus thermophilus monocultures of (A) ST1131 and $\Delta$ ure $C 1131$, (B) ST499 and $\Delta$ ureC499, and (C) ATCC19258 ${ }^{\mathrm{T}}$ and $\Delta$ ureC19258 ${ }^{\mathrm{T}}$. The WT strains were cultured in skim milk flushed with $\mathrm{N}_{2}(\mathrm{O})$, and the $\Delta$ ure $C$ were cultured in skim milk flushed with $\mathrm{N}_{2}(\bullet)$, with $\mathrm{NaHCO}_{3}$ supplementation $(\boldsymbol{\Delta})$ or with $\mathrm{NaHCO}_{3}$ and $\left(\mathrm{NH}_{4}\right)_{2} \mathrm{SO}_{4}$ supplementation (ם). Acidity (\%) corresponds to the amount of acid produced by Streptococcus thermophilus in the skim milk medium. Error bars show SD of the results from at least 3 independent experiments.

\section{Effect of $\mathrm{N}_{2}$ Flushing and $\mathrm{NaHCO}_{3}$ and $\left(\mathrm{NH}_{4}\right)_{2} \mathrm{SO}_{4}$ Supplementation on Acid Production of L. bulgaricus Strains}

Seven strains of L. bulgaricus (LB494, LB496, LB497, LB2038, LB536, LB600, and LB ATCC11842 ${ }^{\mathrm{T}}$ ) were cultured in skim milk with or without $\mathrm{N}_{2}$ flushing to evaluate their $\mathrm{CO}_{2}$ requirement for growth and acidification (Figure 3). Flushing with $\mathrm{N}_{2}$ decreased the amount of $\mathrm{CO}_{2}$ present in the skim milk medium from $2.5 \mathrm{mg} / \mathrm{L}$ to less than $1.49 \mathrm{mg} / \mathrm{L}$.

Strains LB497, LB494, LB2038, and LB536 appeared $\mathrm{CO}_{2}$-responsive because $\mathrm{N}_{2}$ flushing of the culture medium significantly decreased their acidification rates, whereas addition of $\mathrm{NaHCO}_{3}(30 \mathrm{~m} M)$ restored acidification (Figure 3A, B, C, and D). In contrast, neither $\mathrm{N}_{2}$ flushing nor $\mathrm{NaHCO}_{3}$ supplementation modified the acidification rates of LB496 and LB600 (Figure 3E and F). Finally, for ATCC $11842^{\mathrm{T}}$, a faint stimulatory effect on acidification rate was observed after both $\mathrm{N}_{2}$ flushing and $\mathrm{NaHCO}_{3}$ supplementation (Figure 3G). These data established that LB496, LB600, and ATCC11842 ${ }^{\mathrm{T}}$ required no $\mathrm{CO}_{2}$ or less than $1.49 \mathrm{mg} / \mathrm{L} \mathrm{CO}$ in skim milk medium for growth and acidification; we designated such strains " $\mathrm{CO}_{2}$-unresponsive."

The effects of $\mathrm{NH}_{3}$ supplementation were also tested on L. bulgaricus acid production. Supplementation with $\left(\mathrm{NH}_{4}\right)_{2} \mathrm{SO}_{4}$ did not affect acidification rates of the 7 studied strains (Figure 3 ). This result established that the $L$. bulgaricus strains did not require more than 2.7 $\mathrm{mg} / \mathrm{L} \mathrm{NH}_{4}-\mathrm{N}$ in skim milk for growth.

\section{Coculture with $\mathrm{CO}_{2}$-Responsive and $\mathrm{CO}_{2}-$ Unresponsive L. bulgaricus Strains}

We selected the L. bulgaricus strains LB536 $\left(\mathrm{CO}_{2^{-}}\right.$ responsive, Figure 4A) and LB496 $\left(\mathrm{CO}_{2}\right.$-unresponsive, Figure 4B) for cocultures with ST1131 and $\Delta$ ureC1131 in skim milk supplemented with $0.4 \mathrm{~g} / \mathrm{L}$ urea and flushed with $\mathrm{N}_{2}$ gas. Regardless of the L. bulgaricus strain, urease deficiency of $\Delta$ ure $C 1131$ caused a severe decrease (closed circles) in the acidification rate of the 

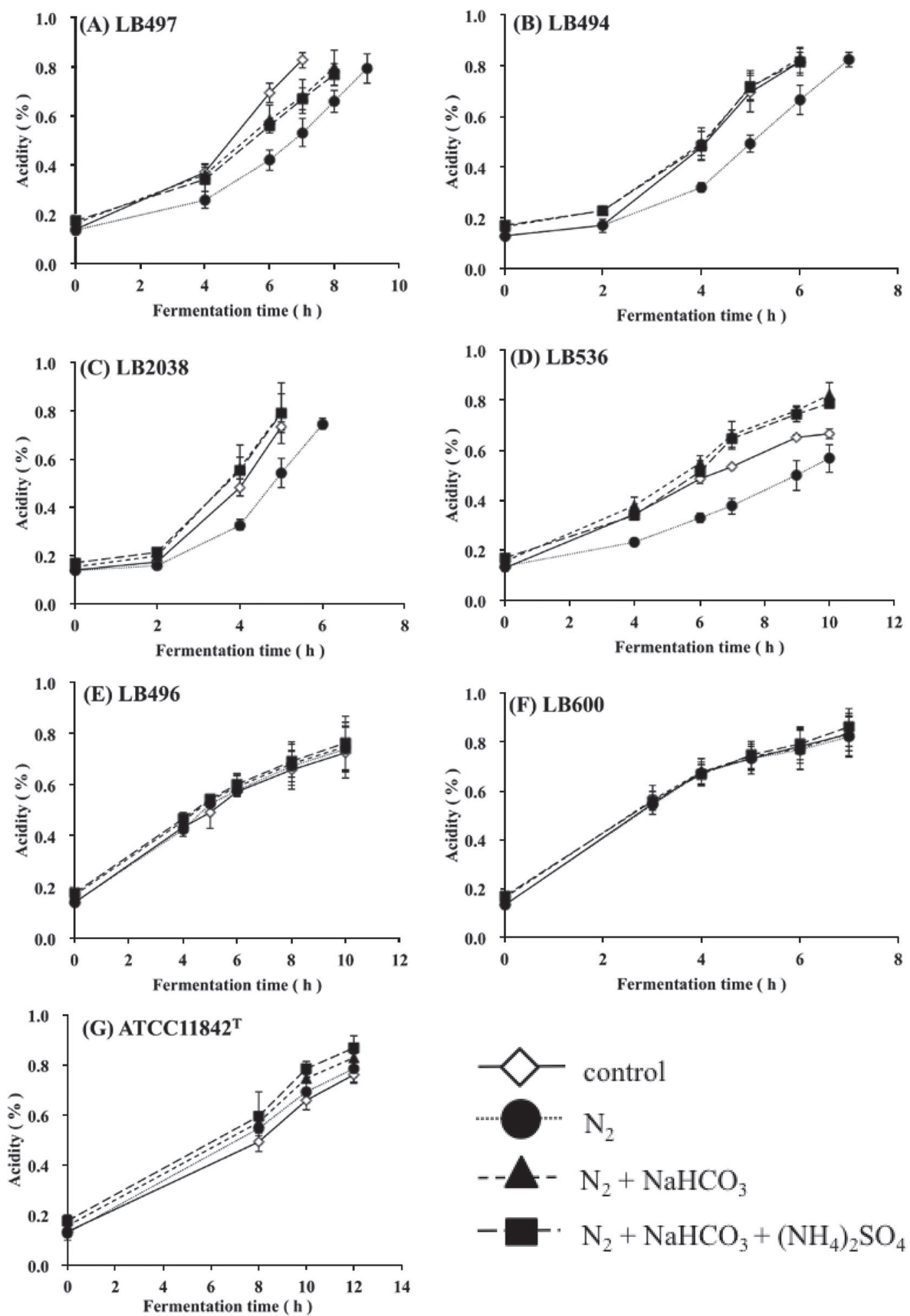

Figure 3. Acidification kinetics of 7 Lactobacillus delbrueckii ssp. bulgaricus strains in various growth media. The L. bulgaricus strains were cultured at $43^{\circ} \mathrm{C}$ in skim milk medium without $(\diamond)$ or with $(\bullet) \mathrm{N}_{2}$ flushing and supplementation with $\mathrm{NaHCO}_{3}(\Delta)$, or with $\mathrm{NaHCO}_{3}$ and $\left(\mathrm{NH}_{4}\right)_{2} \mathrm{SO}_{4}(\mathbf{\square})$. Acidity (\%) corresponds to the amount of acid produced by L. bulgaricus in the skim milk medium. Error bars show SD of the results from at least 3 independent experiments. 

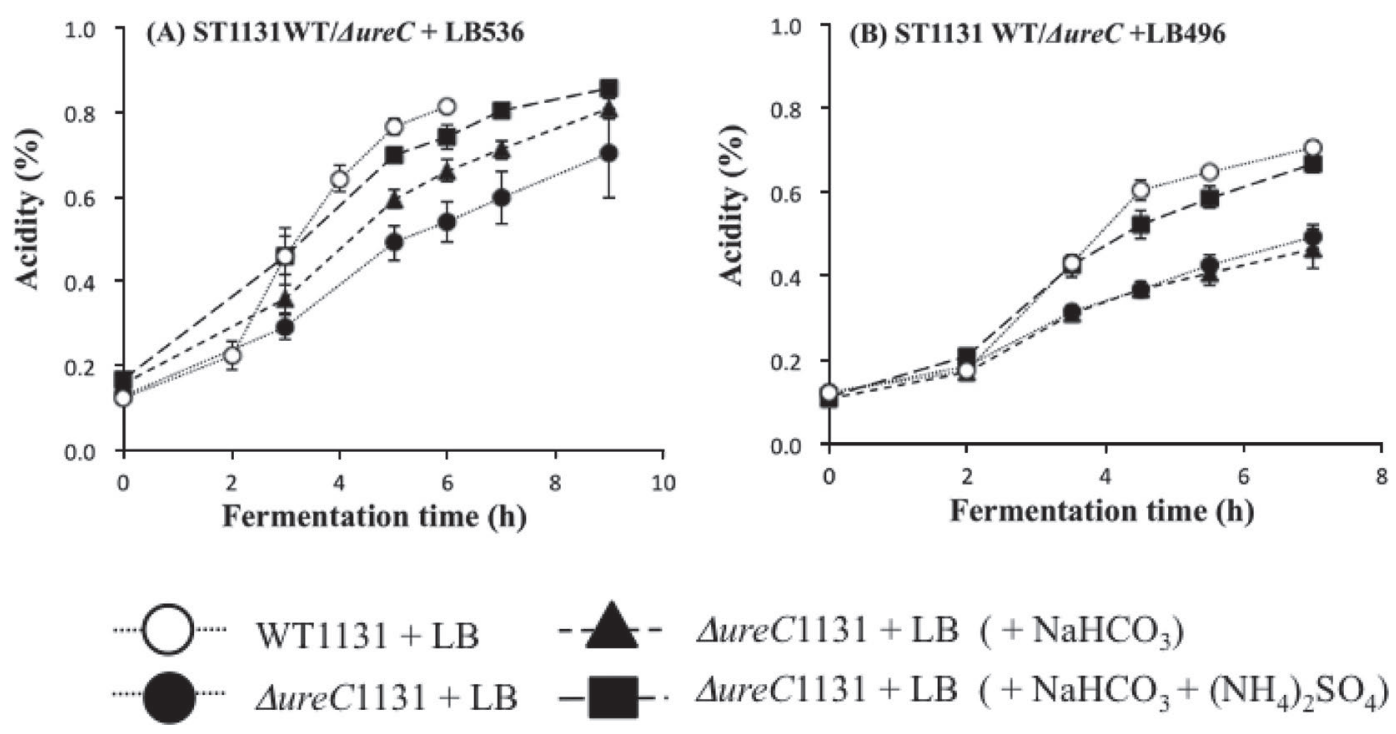

Figure 4. Acidification kinetics of cocultures of Streptococcus thermophilus ST1131 or ST1131 urease-deficient mutants ( $\Delta$ ureC1131) with either Lactobacillus delbrueckii ssp. bulgaricus (A) LB536 $\left(\mathrm{CO}_{2}\right.$-responsive) or (B) LB496 $\left(\mathrm{CO}_{2}\right.$-unresponsive) . Cocultures were performed at $43^{\circ} \mathrm{C}$ in the skim milk medium flushed with $\mathrm{N}_{2}(\mathrm{O}, \boldsymbol{\bullet})$, supplemented with $\mathrm{NaHCO}_{3}(\boldsymbol{\Delta})$, or with $\mathrm{NaHCO}_{3}$ and $\left(\mathrm{NH}_{4}\right)_{2} \mathrm{SO}_{4}(\boldsymbol{\square})$. The open symbol (O) indicates the coculture of Strep. thermophilus wild type (WT) with L. bulgaricus. Closed symbols $(\boldsymbol{\bullet}, \mathbf{\Lambda}$, and $\mathbf{\square})$ indicate the coculture of urease-deficient mutants ( $\triangle$ ureC) with L. bulgaricus. Acidity (\%) corresponds to the amount of acid produced by Streptococcus thermophilus and L. bulgaricus in the skim milk medium. Error bars show SD of the results from at least 3 independent experiments.

cocultures compared with the cocultures involving WT ST1131 (open circles).

To evaluate the effects of $\mathrm{CO}_{2}$ and $\mathrm{NH}_{3}$ provided by urease activity, we monitored the acidification rate of $\Delta$ ureC1131 with each of the $L$. bulgaricus strains in medium supplemented with $\mathrm{NaHCO}_{3}$ with or without $\left(\mathrm{NH}_{4}\right)_{2} \mathrm{SO}_{4}$. The effects of $\mathrm{CO}_{2}$ and $\mathrm{NH}_{3}$ supplementation on acidification rates differed between the $\mathrm{CO}_{2}$-responsive and $\mathrm{CO}_{2}$-unresponsive L. bulgaricus strains cocultured with $\Delta$ ureC1131. In the coculture of $\Delta$ ureC1131 with the $\mathrm{CO}_{2}$-responsive LB536 strain, supplementation with both $\mathrm{NaHCO}_{3}$ and $\left(\mathrm{NH}_{4}\right)_{2} \mathrm{SO}_{4}$ accelerated the acidification rate. In the coculture of $\Delta$ ure $C 1131$ with the $\mathrm{CO}_{2}$-unresponsive LB496 strain, only $\left(\mathrm{NH}_{4}\right)_{2} \mathrm{SO}_{4}$ supplementation stimulated the acidification rate, whereas $\mathrm{NaHCO}_{3}$ supplementation had no effect, as expected. These observations established that $\left(\mathrm{NH}_{4}\right)_{2} \mathrm{SO}_{4}$ supplementation accelerated the acidification in cocultures with the $\Delta$ ure C Strep. thermophilus strain regardless of $\mathrm{CO}_{2}$-responsivness of $L$. bulgaricus co-starter.

\section{Cocultures of Fast- or Slow-Acidifying Strep. thermophilus Strains with $\mathrm{CO}_{2}$-Responsive L. bulgaricus}

To evaluate whether the effect of urease deficiency on acidification in yogurt fermentation depended on the acidification rate of the Strep. thermophilus strain used as a co-starter, 3 WT strains of Strep. thermophilus and their $\triangle$ ure $C$ derivatives were cocultured with the $\mathrm{CO}_{2}$-responsive LB2038 strain in skim milk medium supplemented with $0.4 \mathrm{~g} / \mathrm{L}$ urea and flushed with $\mathrm{N}_{2}$ gas (Figure 5).

The time to reach $0.7 \%$ acidity was $4 \mathrm{~h}$ in the coculture of LB 2038 with the fast-acidifying strains (ST1131 and ST499) but $10.5 \mathrm{~h}$ in the coculture with the slow-acidifying strain ATCC19258 ${ }^{\mathrm{T}}$. However, with all tested strain combinations, the urease deficiency of Strep. thermophilus decreased the acidification rates: the time required to reach $0.7 \%$ acidity increased 1.5 to 2-fold compared with that of cocultures with the WT Strep. thermophilus counterparts and LB2038.

Both $\mathrm{NaHCO}_{3}$ and $\left(\mathrm{NH}_{4}\right)_{2} \mathrm{SO}_{4}$ supplementation accelerated acidification of the cocultures of $\Delta$ ure $C$ strains with L. bulgaricus 2038, except for $\Delta$ ureC $19258^{\mathrm{T}}$, in which supplementation with $\mathrm{NaHCO}_{3}$ and $\left(\mathrm{NH}_{4}\right)_{2} \mathrm{SO}_{4}$ did not have a significant effect.

\section{DISCUSSION}

In this study, we reexamined the effect of urease on acidification rates during yogurt fermentation. There are conflicting reports (Mora et al., 2004; Monnet et al., 2005; Arioli et al., 2009, 2017) regarding the effects of urease on acidification rates in monocultures and 

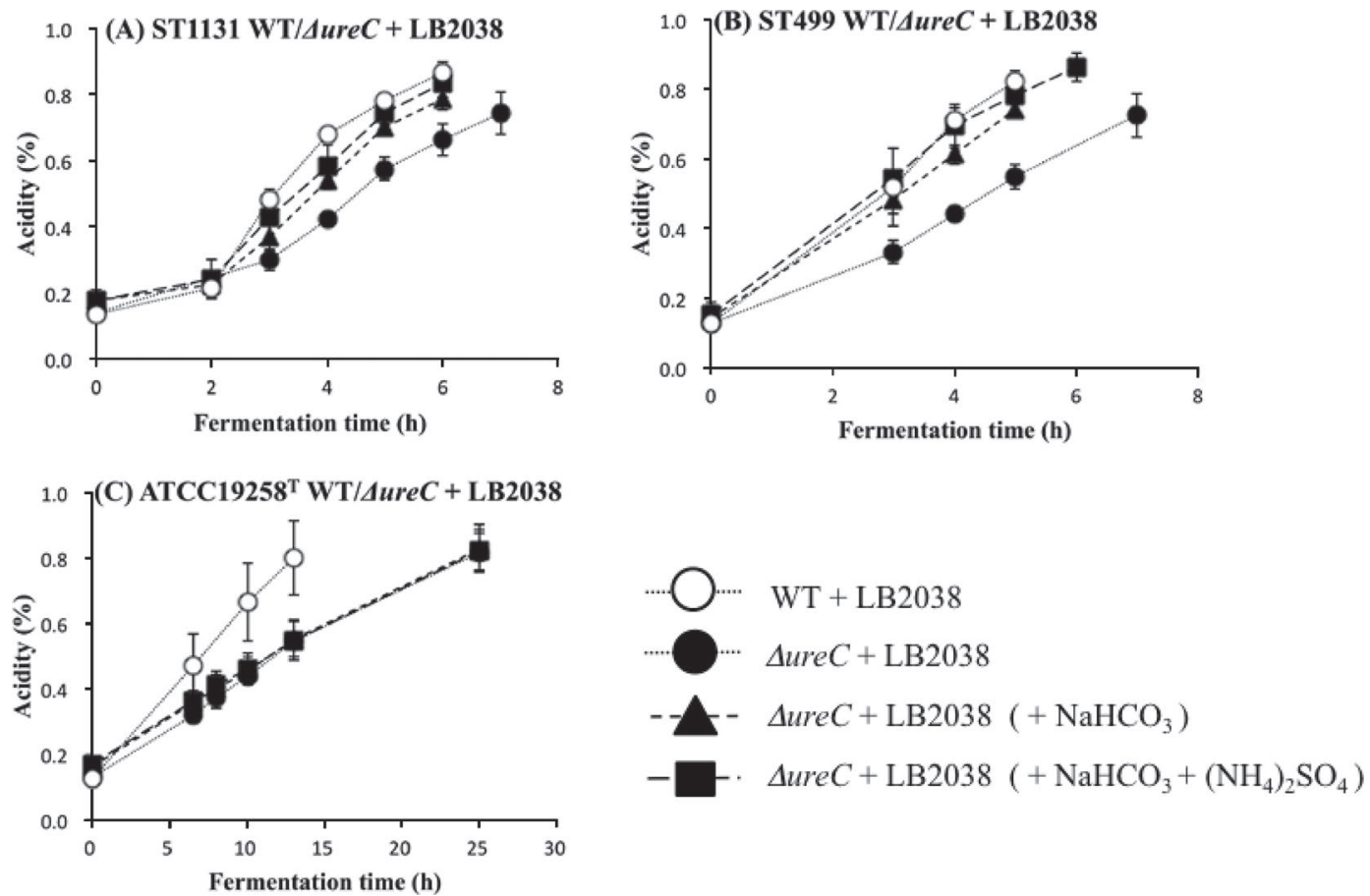

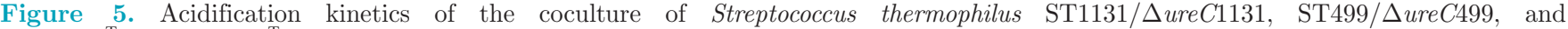
ATCC19258 ${ }^{\mathrm{T}} / \Delta$ ure $19258^{\mathrm{T}}$ with Lactobacillus delbrueckii ssp. bulgaricus LB2038. The cocultures were performed in the skim milk medium with $\mathrm{N}_{2}(\mathrm{O}, \boldsymbol{\bullet})$, supplemented with $\mathrm{NaHCO}_{3}(\boldsymbol{\Delta})$ or $\mathrm{NaHCO}_{3}$ and $\left(\mathrm{NH}_{4}\right)_{2} \mathrm{SO}_{4}(\boldsymbol{\square})$. The open symbol $(\mathrm{O})$ indicates the coculture of Streptococcus thermophilus wild type (WT) with $L$. bulgaricus. Closed symbols $(\boldsymbol{\bullet}, \boldsymbol{\Lambda}$, and $\mathbf{\square})$ indicate the coculture of urease-deficient mutants $(\Delta$ ure $C)$ with $L$. bulgaricus. Acidity (\%) corresponds to the amount of acid produced by Streptococcus thermophilus and L. bulgaricus in the skim milk medium. Error bars show SD of the results from at least 3 independent experiments.

cocultures of Strep. thermophilus and L. bulgaricus. We explain these discrepant reports as follows: (1) nitrogen starvation and formate deficiency encountered by Strep. thermophilus and L. bulgaricus monocultured in milk medium, respectively, did not allow for the effect of urease to be studied under normal physiological conditions; and (2) the limited number of $L$. bulgaricus and Strep. thermophilus strains and combinations that were used did not account for the diversity of strain phenotypes. We addressed these 2 points in the current work. First, we supplemented skim milk medium with casein peptides for Strep. thermophilus monocultures and with sodium formate for $L$. bulgaricus monocultures to prevent starvation during assessment of the effect of urease deficiency on acidification rates. Second, we used several strains of each LAB species. For instance, we used fast- and slow-acidifying Strep. thermophilus strains to construct isogenic ure $C$-deficient mutants $\left(\Delta\right.$ ure $C$ ). We also characterized the $\mathrm{CO}_{2}$ response of several L. bulgaricus strains and used $\mathrm{CO}_{2}$-responsive and $\mathrm{CO}_{2}$-unresponsive strains. Based on our data, we then used 5 strain combinations for cocultures. Together, our data demonstrated that urease is an essential factor for effective protocooperation and yogurt fermentation.

\section{Effect of Urease Deficiency on $\mathrm{CO}_{2}$ and $\mathrm{NH}_{3}$ Production by Strep. thermophilus Strains}

Urease deficiency resulted in dramatic reduction of $\mathrm{CO}_{2}$ and $\mathrm{NH}_{3}$ production, regardless of the strain (Table 2). As expected, we confirmed that urease is the main provider of $\mathrm{CO}_{2}$ and $\mathrm{NH}_{4} \mathrm{~N}$ in Strep. thermophilus cultures. However, between 6.4 and $7.6 \mathrm{mg} / \mathrm{L}$ of $\mathrm{CO}_{2}$ was detected in the $\Delta$ ure $C$ cultures, whereas $\mathrm{CO}_{2}$ was not detected in uninoculated (control) skim milk (Table 2 ), indicating that other enzymes such as carbonate dehydratase provided a small amount of $\mathrm{CO}_{2}$ that can be measured in the absence of urease (Sieuwerts et al., 2010). Conversely, $\mathrm{NH}_{4}-\mathrm{N}$ was not detected in any $\Delta$ ure $C$ cultures, although a trace amount was found in uninoculated milk. This observation indicated that the milk $\mathrm{NH}_{4}-\mathrm{N}$ was consumed by the $\Delta$ ure $C$ strains during their growth. For cultures of WT strains, 210 to 250 $\mathrm{mg} / \mathrm{L}$ of $\mathrm{NH}_{4}-\mathrm{N}$ was measured. These values were below the predicted $359 \mathrm{mg} / \mathrm{L}$ of $\mathrm{NH} 4-\mathrm{N}$ based on the urea concentration in skim milk supplemented with $0.4 \mathrm{~g} / \mathrm{L}$ urea (total urea concentration was $633 \mathrm{mg} / \mathrm{L}$ ). These results indicated that Strep. thermophilus consumed part of the $\mathrm{NH}_{3}$ provided by urease and other enzymes such as glutamate dehydrogenase. 


\section{Effect of Urease Deficiency on the Growth of Strep. thermophilus}

For all 3 strains of Strep. thermophilus, urease deficiency severely decreased acidification rates and bacterial counts; counts of $\Delta$ ure $C$ strains were $10 \%$ that of WT strains (Table 2) in the skim milk medium with (Figure 2) or without $\mathrm{N}_{2}$ flushing (data not shown). These results revealed that urease was important for the growth of both fast- and slow-acidifying strains. However, Pernoud et al. (2004) did not observe significant delay in acidification and growth $\left(\mathrm{OD}_{405}\right)$ of Strep. thermophilus RD672 in the presence of flurofamide, a urease inhibitor. We propose that the effect of urease deficiency was underestimated because the Strep. thermophilus monoculture did not grow efficiently due to nitrogen starvation (lack of supplementation with peptides; Horiuchi and Sasaki, 2012).

To evaluate whether $\mathrm{CO}_{2}$ or $\mathrm{NH}_{3}$ provided by urease affected acidification by Strep. thermophilus, we added $\mathrm{NaHCO}_{3}$ or $\left(\mathrm{NH}_{4}\right)_{2} \mathrm{SO}_{4}$ as sources of $\mathrm{CO}_{2}$ or $\mathrm{NH}_{3}$ to $\Delta$ ure $\mathrm{C}$ monocultures. Supplementation with $\left(\mathrm{NH}_{4}\right)_{2} \mathrm{SO}_{4}$ significantly accelerated the acidification of Strep. thermophilus, whereas supplementation with $\mathrm{NaHCO}_{3}$ had only a slight or no effect (Figure 2). Among the tested strains, stimulation by $\left(\mathrm{NH}_{4}\right)_{2} \mathrm{SO}_{4}$ supplementation was limited in the $\Delta$ ure $C 19258^{\mathrm{T}}$ culture. It may be that the $\mathrm{NH}_{4}$ transporters are deficient in that strain. Despite this specific case, our results established that urease is important for the growth of Strep. thermophilus, mainly through $\mathrm{NH}_{3}$ supply. It is noteworthy that $\left(\mathrm{NH}_{4}\right)_{2} \mathrm{SO}_{4}$ significantly accelerated acidification, even though the medium was supplemented with casein digested peptides, which provided at least 18 types of AA, including glutamate and aspartate that could constitute sources of ammonia nitrogen sources. This observation indicated that the requirement of Strep. thermophilus for ammonia nitrogen cannot be easily substituted by AA nitrogen. Monnet et al. (2005) reported that $\mathrm{NH}_{3}$ supplied by urease could contribute to glutamine synthesis. In agreement, Arioli et al. (2007) reported that urease transcription was activated upon nitrogen limitation and was repressed by glutamate, glutamine, and $\mathrm{NH}_{3}$. Our results also support that $\mathrm{NH}_{3}$ provided by urease is important for AA and nucleic acid metabolism going through glutamine and carbamoyl phosphate in Strep. thermophilus.

\section{Effect of $\mathrm{CO}_{2}$ and $\mathrm{NH}_{3}$ on Acidification by L. bulgaricus}

Although the L. bulgaricus genomes exhibit some decarboxylase genes and they may produce $\mathrm{CO}_{2}$, the $\mathrm{N}_{2}$ flushing of the milk medium revealed that $\mathrm{CO}_{2}$ respon- siveness of $L$. bulgaricus varied among strains (Figure 3 ). Out of the 7 studied L. bulgaricus strains, 4 strains (LB497, LB494, LB2038, and LB536) required $\mathrm{CO}_{2}$ for effective acidification under $\mathrm{N}_{2}$ flushing and 3 strains (LB496, LB600, and ATCC11842 ${ }^{\mathrm{T}}$ ) did not. The former result (Figure 3A, B, C, and D) strongly suggests that the decarboxylase genes in the strains' genomes were not able to provide enough $\mathrm{CO}_{2}$ for optimal growth. Bringel and Hubert (2003) reported that Lactobacillus plantarum required $\mathrm{CO}_{2}$ for the biosynthesis of pyrimidine; this may also be the case for the L. bulgaricus $\mathrm{CO}_{2}$-responsive strains.

Regarding ammonia, Arioli et al. (2017) reported that in the absence of carbon source, $\mathrm{NH}_{3}$ provided by urease brought the intracellular $\mathrm{pH}$ of $L$. bulgaricus MIM91 to an alkaline value and allowed a better homeostasis of the strain metabolic activity. Hence, they suggested that $\mathrm{NH}_{3}$ provided by urease had positive effects on L. bulgaricus, although ammonia supplementation did not increase the intracellular $\mathrm{pH}$ of $L$. bulgaricus grown in skim milk medium. Our study establishes that $\left(\mathrm{NH}_{4}\right)_{2} \mathrm{SO}_{4}$ supplementation did not increase the acidification rates of any of the $7 \mathrm{~L}$. bulgaricus strains. These results strongly suggest that $\mathrm{NH}_{3}$ provided by urease did not directly affect the growth of $L$. bulgaricus strains in milk.

We conclude that the urease of Strep. thermophilus directly affected the acidification of $\mathrm{CO}_{2}$-responsive L. bulgaricus strains through the provision of $\mathrm{CO}_{2}$, whereas $\mathrm{NH}_{3}$ provided by urease activity had no direct effect on $L$. bulgaricus growth.

\section{Function of Urease in Yogurt Fermentation}

In monocultures (Figure 2), the time required to reach $0.4 \%$ acidity increased by 2.5 - to 4 -fold due to urease deficiency but increased by only 1.6- to 2 -fold in cocultures.

The first observation is that delay in acidification was stronger in Strep. thermophilus monocultures than in cocultures with $L$. bulgaricus. It could be that L. bulgaricus provided a limited amount of ammonia nitrogen to Strep. thermophilus in coculture and that L. bulgaricus contributed to the acidification and partly masked the effect of urease deficiency. With all 5 combinations of Strep. thermophilus and L. bulgaricus, the urease deficiency of Strep. thermophilus significantly decreased the acidification rate (Figures 4 and 5). However, the mode of action differed between $\mathrm{CO}_{2}$-responsive and $\mathrm{CO}_{2}$-unresponsive L. bulgaricus strains. As shown in our work, with $\mathrm{CO}_{2}$-responsive strains (such as LB536, Figure $4 \mathrm{~A}$ ), the use of the $\Delta$ ureC1131 strain led to a decreased acidification rate, which could be overcome by the supplementation with $\mathrm{NaHCO}_{3}$ and $\left(\mathrm{NH}_{4}\right)_{2} \mathrm{SO}_{4}$. 
In cocultures of $\mathrm{CO}_{2}$-unresponsive $L$. bulgaricus strains (such as LB496, Figure 4B) with $\Delta$ ure C1131, the acidification rate was stimulated only by $\left(\mathrm{NH}_{4}\right)_{2} \mathrm{SO}_{4}$ supplementation and not by $\mathrm{NaHCO}_{3}$ addition.

We showed in this study that urease deficiency affected the acidification of all tested protocooperations regardless of the strains' phenotypes in terms of acidification speed for Strep. thermophilus or $\mathrm{CO}_{2}$-responsiveness for $L$. bulgaricus. The effects of urease deficiency are mediated (1) by a shortage of ammonia nitrogen, which affects all Strep. thermophilus strains, and (2) by a shortage in $\mathrm{CO}_{2}$, which only affects the growth of $\mathrm{CO}_{2}$-responsive L. bulgaricus strains. Consequently, the main effect of urease deficiency is mediated through the ammonia nitrogen limitation rather than $\mathrm{CO}_{2}$ shortage. Our data established that urease is essential for effective protocooperation and yogurt acidification by Strep. thermophilus and L. bulgaricus.

\section{REFERENCES}

Arioli, S., G. Della Scala, M. C. Remagni, M. Stuknyte, S. Colombo, S. Guglielmetti, I. De Noni, E. Ragg, and D. Mora. 2017. Streptococcus thermophilus urease activity boosts Lactobacillus delbrueckii ssp. bulgaricus homolactic fermentation. Int. J. Food Microbiol. 247:55-64.

Arioli, S., C. Monnet, S. Guglielmetti, C. Parini, I. De Noni, J. Hogenboom, P. M. Halami, and D. Mora. 2007. Aspartate biosynthesis is essential for the growth of Streptococcus thermophilus in milk, and aspartate availability modulates the level of urease activity. Appl. Environ. Microbiol. 73:5789-5796.

Arioli, S., P. Roncada, A. M. Salzano, F. Deriu, S. Corona, S. Guglielmetti, L. Bonizzi, A. Scaloni, and D. Mora. 2009. The relevance of carbon dioxide metabolism in Streptococcus thermophilus. Microbiology 155:1953-1965.

Biswas, I., A. Gruss, S. D. Ehrlich, and E. Maguin. 1993. High-efficiency gene inactivation and replacement system for gram-positive bacteria. J. Bacteriol. 175:3628-3635.

Bradford, M. M. 1976. A rapid and sensitive method for the quantitation of microgram quantities of protein utilizing the principle of protein-dye binding. Anal. Biochem. 72:248-254.

Bringel, F., and J. Hubert. 2003. Extent of genetic lesions of the arginine and pyrimidine biosynthetic pathways in Lactobacillus plantarum, L. paraplantarum, L. pentosus, and L. casei: prevalence of $\mathrm{CO}_{2}$-dependent auxotrophs and characterization of deficient. Appl. Environ. Microbiol. 69:2674-2683.
Driessen, F. M., F. Kingma, and J. Stadhouders. 1982. Evidence that Lactobacillus bulgaricus in yogurt is stimulated by carbon dioxide produced by Streptococcus thermophilus. Neth. Milk Dairy J. $36: 135-144$.

Food Safety and Standards Authority of India. 2015. Pages 11-13 in Manual of Methods of Analysis of Foods (Milk and Milk Products) - A Laboratory Manual. Food Safety and Standards Authority of India, Ministry of Health and Family Welfare, Government of India, New Delhi, India.

Galesloot, T. E., F. Hassing, and H. A. Veringa. 1968. Symbiosis in yoghurt. I. Stimulation of Lactobacillu bulgaricus by a factor produced by Streptococcus thermophilus. Neth. Milk Dairy J. 22:50-63.

Horiuchi, H., N. Inoue, E. Liu, M. Fukui, Y. Sasaki, and T. Sasaki. 2009. A method for manufacturing superior set yogurt under reduced oxygen conditions. J. Dairy Sci. 92:4112-4121.

Horiuchi, H., and Y. Sasaki. 2012. Short communication: Effect of oxygen on symbiosis between Lactobacillus bulgaricus and Streptococcus thermophilus. J. Dairy Sci. 95:2904-2909.

Iyer, R., S. K. Tomar, T. Uma Maheswari, and R. Singh. 2010. Streptococcus thermophilus strains: Multifunctional lactic acid bacteria. Int. Dairy J. 20:133-141.

Maguin, E., H. Prevost, S. D. Ehrlich, and A. Gruss. 1996. Efficient insertional mutagenesis in lactococci and other gram-positive bacteria. J. Bacteriol. 178:931-935.

Monnet, C., D. Mora, and G. Corrieu. 2005. Glutamine synthesis is essential for growth of Streptococcus thermophilus in milk and is linked to urea catabolism. Appl. Environ. Microbiol. 71:3376-3378.

Mora, D., E. Maguin, M. Masiero, C. Parini, G. Ricci, P. L. Manachini, and D. Daffonchio. 2004. Characterization of urease genes cluster of Streptococcus thermophilus. J. Appl. Microbiol. 96:209-219.

Pernoud, S., C. Fremaux, A. Sepulchre, G. Corrieu, and C. Monnet. 2004. Effect of the metabolism of urea on the acidifying activity of Streptococcus thermophilus. J. Dairy Sci. 87:550-555.

Sasaki, Y., H. Horiuchi, H. Kawashima, T. Mukai, and Y. Yamamoto. 2014. NADH oxidase of Streptococcus thermophilus 1131 is required for the effective yogurt fermentation with Lactobacillus delbruecki ssp. bulgaricus 2038. Biosci. Microbiota Food Health 33:31-40.

Sieuwerts, S., D. Molenaar, S. A. F. T. Van Hijum, M. Beerthuyzen, M. J. A. Stevens, P. W. M. Janssen, C. J. Ingham, F. A. M. De Bok, W. M. De Vos, and J. E. T. Van Hylckama Vlieg. 2010. Mixed-Culture transcriptome analysis reveals the molecular basis of mixed-culture growth in Streptococcus thermophilus and Lactobacillus bulgaricus. Appl. Environ. Microbiol. 76:7775-7784.

Tamime, A. Y., and R. K. Robinson. 2007. Yoghurt-Science and Technology. 3rd ed. Woodhead Publishing Limited, Cambridge, UK.

Veringa, H. A., T. E. Galesloot, and H. Davelaar. 1968. Symbiosis in yoghurt. II. Isolation and identification of a growth factor for Lactobacillus bulgaricus produced by Streptococcus thermophilus. Neth. Milk Dairy J. 22:114-120.

Weerathilake, W. A. D. V., D. M. D. Rasika, J. K. U. Ruwanmali, and M. A. D. D. Munasinghe. 2014. The evolution, processing, varieties and health benefits of yogurt. Int. J. Sci. Res. Publ. 4:1-10. 